\title{
Delay in Breast Cancer Treatments During the First COVID-19 Lockdown. A Multicentric Analysis of 432 Patients
}

\author{
GIANLUCA VANNI ${ }^{1}$, GIOVANNI TAZZIOLI ${ }^{2}$, MARCO PELLICCIARO $^{1}$, MARCO MATERAZZO $^{1}$, \\ ORSARIA PAOLO ${ }^{3}$, FRANCESCA CATTADORI $^{4}$, FRANCESCA COMBI $^{2-5}$, SIMONA PAPI $^{2}$, \\ CHIARA ADRIANA PISTOLESE ${ }^{6}$, MARIA COTESTA ${ }^{1}$, FRANCESCA SANTORI $^{1}$, JONATHAN CASPI ${ }^{7}$, \\ AGOSTINO CHIARAVALLOTI ${ }^{8,9}$, SAVERIO MUSCOLI $^{10}$, VITTORIO LOMBARDO $^{11}$, ANTONELLA GRASSO $^{3}$, \\ LORENZA CAGGIATI $^{3}$, ROBERTA RASELLI ${ }^{4}$, DANTE PALLI ${ }^{4}$, VITTORIO ALTOMARE ${ }^{3}$, \\ ROLANDO MARIA D'ANGELILLO ${ }^{12}$, LEONARDO PALOMBI $^{8}$ and ORESTE CLAUDIO BUONOMO ${ }^{1}$ \\ ${ }^{1}$ Breast Unit, Department of Surgical Science, PTV: Policlinico Tor Vergata University, Rome, Italy; \\ ${ }^{2}$ Division of Breast Surgical Oncology Department of Medical and Surgery, \\ Maternal-infantile and Adult Sciences, University Hospital of Modena and Reggio Emilia, Modena, Italy; \\ ${ }^{3}$ Department of Breast Surgery, University Campus Bio-Medico, Rome, Italy; \\ ${ }^{4}$ Breast Surgery, Breast Unit, "Guglielmo da Saliceto" Hospital, Piacenza, Italy; \\ ${ }^{5}$ PhD Clinical and Experimental Medicine, University of Modena and Reggio Emilia, Modena, Italy; \\ ${ }^{6}$ Department of Diagnostic Imaging and Interventional Radiology, \\ Molecular Imaging and Radiotherapy, Policlinico Tor Vergata University, Rome, Italy; \\ ${ }^{7}$ Tor Vergata School of Medicine and Surgery, Tor Vergata University, Rome, Italy; \\ ${ }^{8}$ Department of Biomedicine and Prevention, Tor Vergata University, Rome, Italy; \\ ${ }^{9}$ IRCCS Neuromed, UOC Medicina Nucleare, Pozzilli, Italy; \\ ${ }^{10}$ Department of Cardiovascular Disease, Tor Vergata University, Rome, Italy; \\ ${ }^{11}$ Department of General Surgery, I.R.C.C.S. Centro Neurolesi Bonino Pulejo P.O. Piemnote, Messina, Italy; \\ ${ }^{12}$ Radiotherapy Unit, Department of Oncology and Hematology, Policlinico Tor Vergata University, Rome, Italy
}

\begin{abstract}
Background/Aim: Extraordinary restrictions aimed to limit Sars-CoV-2 spreading; they imposed a total reorganization of the health-system. Oncological treatments experienced a significant slowdown. The aim of our multicentric retrospective study was to evaluate screening suspension and surgical treatment delay during COVID-19 and the impact on breast cancer presentation. Patients and Methods: All patients who underwent breast surgery from March 11, 2020 to May 30, 2020 were evaluated and considered as the Lockdown group. These patients were compared with similar patients of the previous year, the Pre-Lockdown group. Results: A total of 432 patients were evaluated; $n=223$ and $n=209$ in the Lockdown
\end{abstract}

This article is freely accessible online.

Correspondence to: Pellicciaro Marco, MD, Breast Unit, Department of Surgical Science, Policlinico Tor Vergata University, Viale Oxford 81, 00133, Rome, Italy. Tel: +39 3280221779, e-mail: marcopell62@gmail.com

Key Words: COVID-19, breast cancer, screening suspension, lockdown, oncological treatments delay. and Pre-lockdown-groups, respectively. At univariate analysis, waiting times, lymph-nodes involvement and cancer grading, showed a statistically significant difference $(p<0.05)$. Multivariate analysis identified waiting-time on list $(O R=1.07)$ as a statistically significant predictive factor of lymph node involvement. Conclusion: Although we did not observe a clinically evident difference in breast cancer presentation, we reported an increase in lymph node involvement.

Sars-CoV-2 infection has dramatically spread worldwide since the beginning of 2020 (1). Due to rapid human-tohuman transmission and in order to limit the viral spread, on March 10, 2020, the government has implemented extraordinary restrictions (2). These measures changed our daily routine and forced a reorganization of the Health system (3). During the pandemic, especially at the beginning of the lockdown, only urgent medical services were guaranteed while oncological diagnostic procedures and treatments suffered a significant slowdown (3). Many national and international scientific societies and research groups published recommendations aiming to prioritize breast cancer management strategies, preserve hospital resources for COVID-19 and reduce the risk of cross- 
infection (4-6). Regardless of the recommendations, breast cancer screening programs were temporarily suspended (7). Even though breast cancer is the most common cancer in women worldwide, in the last years there has been a decrease in mortality (8). Additionally, invasive breast surgeries (e.g. mastectomy) have decreased along the years. Both these favourable outcomes have been made possible partially thanks to the improvement in early breast cancer diagnosis achieved by the screening programs (9). Many researches have reported that in addition to the improvement in survival, there is a significant reduction in breast cancer diagnosed by physical examination (e.g . palpable lesion) (7, 10-12). We hypothesized that screening suspension and surgical treatment delay could alter the clinical presentation and features of breast cancer.

The aim of our multicentric retrospective study was to evaluate the impact of screening suspension and treatment delay during the COVID-19 lockdown, on breast cancer clinical presentation, diagnosis and surgical treatments.

\section{Patients and Methods}

Study design. In our multicentric study we retrospectively analyzed data from four Italian Brest Units: "Azienda OspedalieroUniversitaria Policlinico" hospital of Modena, "Gulielmo da Saliceto" hospital Piacenza, Tor Vergata University Hospital Rome and Campus Bio-Medico University hospital Rome. All patients who underwent breast surgery from March 11, 2020 to May 30, 2020 were evaluated in our study and were considered as the Lockdown group. These patients were compared with patients who undergone breast surgery during the same period of the previous year (March 11, 2019 to May 30, 2019), defined as the Pre-Lockdown group.

Four hundred and thirty-two $(n=432)$ patients were evaluated in the study. Patients who did not undergo oncological surgery were excluded from the analysis. The manuscript was approved by the local Ethical Committee of the Fondazione Policlinico Tor Vergata (reference 122/20).

Variable and outcome definition. The number of surgical procedures performed by each Breast Unit during the studied periods were reported. For each patient, date of diagnosis, admission, surgery and discharge were collected.

Preoperative diagnosis was obtained through cytological examination or biopsy as core needle biopsy or Vacuum assisted biopsy.

Waiting time on list was reported in days, defined as the time between histological or cytological examination and date of surgery. Data regarding age and prior administration of neoadjuvant chemotherapy were collected from clinical notes. Reoperation was recorded when a second surgery was performed within 3 months from the primary procedure.

Surgical procedures were distinguished between breast conservative surgery and breast invasive surgery. Breast conservative surgery included all procedures with a partial gland removal. Alternatively, breast invasive surgery comprised the complete removal of the glandular tissue with or without sparing the nipple areola complex (mastectomy). Preoperative image-guided wire localization was reported for breast conservative surgery cases.
The axillary procedure was analysed as well. Patients without clinical or radiological evidence of lymph nodes involvement underwent sentinel lymph node biopsy (SLNB). Otherwise, patients with axillary involvement or SLNB positivity underwent axillary lymph node dissection (ALND). Number of nodes removed during ALND and the degree of node involvement within specimens were reported and analyzed. Length of hospital stay was reported in days, considered as the time between hospital admission and discharge.

Data from surgical specimens were included in the study. Tumor maximum diameters were collected and reported in millimetres. Pathological staging was based on recommendations from AJCC 2018 (edition VIII) for TNM classification. Tumor grading was evaluated according to the Nottingham Histologic Score system (the Elston-Ellis modification of Scarff-Bloom-Richardson grading system). Estrogen receptor (ER), Progesterone receptor (PR) and Ki67 index were expressed as percentage of positive cells in the specimens studied through immunohistochemistry. Overexpression of Her2 gene (HER2+) was identified by immunohistochemistry or by fluorescent in situ hybridization (FISH), as indicated by the recommendations of the 2018 ASCO/CAP, reported as a dichotomous variable (HER+ yes/no).

Statistical analysis. All data were collected into the EXCEL database (Microsoft, Washington, DC, USA). For continuous variables, we calculated medians and ranges. The $t$-test was used to determine whether there were significant differences between the two groups. Categorical data were recorded in numbers and percentages. Analysis was performed using the Fisher's exact test in case of dichotomous variables or Monte Carlo test for non-dichotomous variables. Variables with assigned $p$-values $<0.05$ were considered statistically significant. Cox regression was used for multivariate analysis. All the statistical analysis was performed in SPSS statistical package version 23.0 (SPSS Inc., Chicago, IL, USA).

\section{Results}

From March 11, 2020 to May 30, 2020 a total of 223 patients underwent breast surgery (Lockdown group) compared to 209 treated in the same period of the previous year (Pre-Lockdown group). Twenty patients of the Lockdown group (8.9\%) underwent non-oncological surgery (reconstructive) and were excluded from the analysis. Accordingly, 37 cases of the PreLockdown group (17.9\%) were excluded as well, $p<0.05$.

Median age was 62 [35-90] years in the Lockdown group and 60.8 [21-89] years in the Pre-lockdown group, $p=0.196$. Among the Lockdown group, preoperative diagnosis assessment was performed in 32 cases by cytological examination (15.7\%) and in 187 by biopsy (92.1\%). In the Pre-Lockdown group, $24(13.9 \%)$ patients underwent cytological examination and 159 (92.4\%) were biopsied. Both variables did not show any statistically significant difference with $p$-values of 0.066 and 1.000 , respectively. Upon specimen examination, 48 (27.9\%) patients presented with in situ breast carcinoma in the Lockdown group vs. 24 (18.9\%) in the control group, $p=0.065$. Twenty-eight (13.8\%) patients presented ipsilateral node involvements in the Lockdown $v s$. $19(11.4 \%)$ patients in the Pre-Lockdown group, $p=0.439$. 
Table I. Distribution of type of surgery between groups.

\begin{tabular}{lccc}
\hline & $\begin{array}{c}\text { Lockdown } \\
\text { group } \\
(\mathrm{n}=203)\end{array}$ & $\begin{array}{c}\text { Pre-lockdown } \\
\text { group } \\
(\mathrm{n}=172)\end{array}$ & $p$-Value \\
\hline Mastectomy & $62(30.5 \%)$ & $45(26.2 \%)$ & 0.361 \\
Conservative Surgery & $141(69.5 \%)$ & $121(70.3 \%)$ & 0.649 \\
$\quad$ Wire localization & $110(71 \%)$ & $70(57.9 \%)$ & 0.060 \\
SNLB & $175(86.2 \%)$ & $153(87.9 \%)$ & 0.647 \\
SNLB positive & $30(17.1 \%)$ & $14(9.1 \%)$ & $\mathbf{0 . 0 3 5}$ \\
ALND & $58(28.6 \%)$ & $33(20.0 \%)$ & $\mathbf{0 . 0 3 9}$ \\
ALND N+ & $28(48.3 \%)$ & $19(57.6 \%)$ & 0.513 \\
ALND SNLB positive & $30(51.7 \%)$ & $14(42.4 \%)$ & 0.513 \\
\hline
\end{tabular}

SNLB: Sentinel lymph node biopsy; ALND: axillary lymph nodes dissection; ALND SNLB positive: axillary lymph nodes found positive after sentinel lymph node at frozen sections. Bold values indicate statistical significance.

Administration of neoadjuvant therapy was carried out in 19 patients $(9.3 \%)$ in the Lockdown group and in 16 patients $(9.3 \%)$ in the Pre-Lockdown group, with no statistically significant difference, $p=1.000$. Waiting time on list, the time between biopsy/cytological examination and surgery, was shorter in the Pre-Lockdown group: mean values of 42 [10220] days vs. 56 [6-134] days, showing a statistically significant difference, $p<0.05$. However, waiting time on list adjusted for other factors was the only factor exhibiting an increased risk for nodes involvement when analysed as a dichotomous variable in a logistic binary regression.

Breast conservative surgery was performed in $141(69.5 \%)$ patients in the Lockdown group, and 100 (71\%) of these cases required preoperative image-guided wire localization. In the Pre-Lockdown group, 121 (70.3\%) cases underwent breast conservative surgery and wire localization was required in $70(57.9 \%)$ of them. Both these parameters did not show any statistically significant difference $p=0.6491$ and $p=0.060$, respectively. Types of surgery and relative $p$ values are shown in Table I.

SNLB was performed in $175(86.2 \%)$ cases in the Lockdown group and $30(17.1 \%)$ cases were found positive for cancer at frozen section examination. In the Pre-Lockdown group, 153 patients $(87.9 \%)$ underwent SNLB and cancer was recorded in 14 cases $(9.1 \%)$. Incidence of lymph nodes positivity through SNLB showed a statistically significant difference, $p=0.035$. Conversely, indications for SNLB did not show statistical significance, $p=0.647$ (Table I).

ALND was performed in $58(28.6 \%)$ patients in the Lockdown group, compared to 33 cases $(20.0 \%)$ in the control group, showing a statistically significant difference with $p=0.039$. Indications for ALND are presented in Table I. Number of lymph nodes removed during ALND and number of negative results at pathological examination did not exhibit statistically significant differences between the groups with respective $p$-values of 0.499 and 0.495 .

Length of hospital stay was comparable between the groups without showing a statistically significant difference, $p=0.436$. Median hospitalization time was 2 days (range $=0$ 91 days) in the Lockdown and 2 days (range $=0-93$ days) in the Pre-Lockdown group.

At pathological examination of Lockdown group, 145 (63\%) cases were determined as ductal carcinoma, 32 $(15.8 \%)$ as lobular carcinoma and $26(11.3 \%)$ were defined as others. In the Pre-Lockdown group, 133 (76\%), 20 $(11.5 \%)$ and $18(9.7 \%)$ were determined as ductal carcinoma, lobular carcinoma and others, respectively. No statistically significant differences were found, and the $\mathrm{p}$ values were $0.292,0.294$ and 0.0196 , respectively. One hundred and fifty (74\%) cases of the Lockdown group were invasive carcinoma $v s .137$ (78\%) in the control group, $(p=0.278)$.

Maximum diameter of lesions did not show a statistically significant difference between the groups, $p=0.323$. Median tumor diameters were $12 \mathrm{~mm}$ (range=6-80 $\mathrm{mm}$ ) in the Lockdown group and $13 \mathrm{~mm}$ (range=4-90 $\mathrm{mm}$ ) in the control group. $\mathrm{T}$ distribution between the groups did not show a statistically significant difference, $p=0.489$, depicted in Table II.

Lymph node involvement exhibited a statistically significant difference between the groups $(p=0.031)$, grading of the involvement is presented in Table II. The Lockdown group exhibited higher incidence of N2compared to the Pre-Lockdown group ( $8 \%$ vs. $2 \%$ ), and the difference was statistically significant with $p<0.05$. Four patients $(1.97 \%)$ presented with metastatic breast cancer disease in the Lockdown group compared to 1 case $(0.58 \%)$ in the Pre-Lockdown group, $p=0.380$. Pathological specimen prognostic and predictive factors are shown in Table III. All these variables did not show statistically significant differences. Nonetheless, tumor grading was different among the groups $(p=0.032)$ and its distribution is depicted in Table III.

Incidence of reoperation was comparable in the two groups $(p=0.512)$ with $25(12 \%)$ and $17(10 \%)$ cases in Lockdown and Pre-lockdown groups, respectively. At logistic binary regression, waiting time was the variable associated with increased risk for lymph nodes involvement (univariate $p=0.008$ ). Differently, tumor grading was not a statistically significant factor for predicting lymph nodes major involvement, $p=0.208$. Other factors analyzed with logistic regression are presented in Table IV. Multivariate logistic regression analysis identified waiting time on list (considering 10 days) (OR:1.07) as a statistically significant factor $(p=0.017)$, predictive of lymph nodes major involvement. Other factors analyzed by multivariate analysis are depicted in Table IV. 
Table II. TNM distribution between groups with relative p-values, absolute numbers and (percentages).

\begin{tabular}{lccc}
\hline & $\begin{array}{c}\text { Lockdown } \\
\text { group } \\
(\mathrm{n}=203)\end{array}$ & $\begin{array}{c}\text { Pre-lockdown } \\
\text { group } \\
(\mathrm{n}=172)\end{array}$ & $p$-Value \\
\hline $\mathrm{T}$ T is & $26(12.8 \%)$ & $15(8.7 \%)$ & 0.493 \\
$\mathrm{~T} 1$ & $131(64.5 \%)$ & $112(65.8 \%)$ & \\
$\mathrm{T} 2$ & $31(15.3 \%)$ & $36(20.9 \%)$ & \\
$\mathrm{T} 3$ & $9(4.4 \%)$ & $4(2.3 \%)$ & \\
$\mathrm{T} 4$ & $3(1.5 \%)$ & $3(1.7 \%)$ & $\mathbf{0 . 0 3 1}$ \\
$\mathrm{N}$ & & & \\
$\mathrm{N} 0$ & $121(59.1 \%)$ & $105(60.3 \%)$ & \\
$\mathrm{N} 1$ & $24(11.8 \%)$ & $21(12.2 \%)$ & \\
$\mathrm{N} 2$ & $16(8 \%)$ & $4(2.3 \%)$ & \\
$\mathrm{N} 3$ & $3(1.5 \%)$ & $5(2.8 \%)$ & \multirow{2}{*}{0.380} \\
$\mathrm{M}$ & & $173(99.4 \%)$ & \\
M0 & $199(98 \%)$ & $1(0.6 \%)$ & \\
M1 & $4(2 \%)$ & & \\
\hline
\end{tabular}

T: Tumor; N: lymph nodes; M: metastasis. Bold values indicate statistical significance.

\section{Discussion}

The spread of Sars-CoV2 reached pandemic dimensions in the last months with around 43 million infections worldwide (13). Due to rapid human transmission and in order to limit viral spread, many countries are implementing severe restrictions (2). These measures have altered our daily routine and forced a reorganization of the Health system (3). Accordingly, this reorganization includes resources reallocation toward COVID19 as well as temporary suspension of non-urgent medical services (3). Especially at the beginning of the lockdown, oncological procedures suffered a significant slowdown (3). In this regard, most routine oncological preventive activities were suspended (6). Although the number of COVID-19 cases in Italy is decreasing and despite the return to routine life, breast cancer screening programs are still temporarily scaled down (2-7).

Although breast cancer is the most frequent cancer and represents the leading cause of oncological death among women worldwide; latest statistics suggest that there has been an improvement in term of prognosis $(14,15)$. Both, empowerment of breast cancer treatments and higher incidence of early diagnosis, due to the screening, have led to this improvement (9-16). The benefits of screening are largely attributed to the ability to diagnose breast cancer in earlier stages (17). This is a fundamental factor responsible for reducing recurrence and demolitive surgery and increasing survival rate (18).

Absolute number of surgical procedures during the COVID-19 outbreak are comparable with the same period of the previous year (2019). According to the restrictive measures and scientific recommendations, we observed a
Table III. Prognostic and predictive factors between groups.

\begin{tabular}{lccc}
\hline & $\begin{array}{c}\text { Lockdown } \\
\text { group } \\
(\mathrm{n}=203)\end{array}$ & $\begin{array}{c}\text { Pre-lockdown } \\
\text { group } \\
(\mathrm{n}=172)\end{array}$ & $p$-Value \\
\hline Diameters & $12 \mathrm{~mm}[6-80]$ & $13 \mathrm{~mm}[4-90]$ & 0.323 \\
ER & $79 \%[0-100]$ & $78 \%[0-100]$ & 0.305 \\
PR & $54 \%[0-100]$ & $52 \%[0-100]$ & 0.352 \\
Ki67 & $15 \%[1-80]$ & $16 \%[3-80]$ & 0.054 \\
Grading & & & $\mathbf{0 . 0 3 2}$ \\
G1 & $27(13.3 \%)$ & $37(21.5 \%)$ & \\
G2 & $100(49.2 \%)$ & $65(37.8 \%)$ & \\
G3 & $52(25.6 \%)$ & $36(20.9 \%)$ & \\
HER2 & & & 0.698 \\
Negative & $77(38.1 \%)$ & $70(40.7 \%)$ & \\
Score 1 & $54(26.7 \%)$ & $51(29.65 \%)$ & \\
Score 2 & $10(5 \%)$ & $5(2.9 \%)$ & \\
Score 3 & $11(5.4 \%)$ & $8(4.6 \%)$ & \\
\hline
\end{tabular}

significant reduction in non-oncological surgical procedure (reconstructive surgery) $(6,7,19,20)$. During the lockdown, most national and international guidelines recommended that reconstruction procedures should be deferred $(21,22)$. Waiting lists for breast reconstructive surgery could become clogged and would bring about a psychological impact on women's quality of life (23). In order to avoid further delays, physicians have increased the number of oncological surgical procedures $(24,25)$. In fact, the number of oncological procedures was higher during the lockdown.

Waiting time on list and the time between biopsy/ cytological examination to surgery were significantly longer in the Lockdown group. This delay can be attributed to the slowdown of oncological treatments during the lockdown due to the Health system reorganization and resources reallocation (3). Additionally, patients' anxiety and treatment refusals could have contributed to the delay (26).

Despite breast cancer screening suspension, we did not observe an increase in primary tumor dimensions calculated as maximum diameter and relative $\mathrm{T}$ stage of the disease. In accordance with this result, incidence of mastectomy and conservative breast surgery without radiological wire localization (palpable lesions) were comparable between the two groups. Many Italian studies have reported a reduction in breast cancer diagnosed by physical examination as well as in mastectomies due to early detection through screening $(15,27$, 28). The short timeframe between the screening suspension and our analysis could explain this result. In fact, the time between diagnosis assessment and surgery is longer than 1 month. Thus, in the coming months we could probably observe tumors with larger dimensions or more clinically evident. 
Table IV. Predictive factors of lymph node involvement. Univariate and multivariate analysis.

\begin{tabular}{|c|c|c|c|c|c|c|}
\hline \multirow[b]{2}{*}{ Predictive factors } & \multicolumn{3}{|c|}{ Univariate } & \multicolumn{3}{|c|}{ Multivariate } \\
\hline & OR & $95 \% \mathrm{CI}$ & $p$-Value & OR & $95 \% \mathrm{CI}$ & $p$-Value \\
\hline Waiting time (10 days) & 1.07 & $1.01-1-13$ & 0.008 & 1.07 & $1.01-1.13$ & 0.017 \\
\hline Tumor grading & 1.16 & $0.83-1.64$ & 0.371 & & & 0.208 \\
\hline Patient age & 1.00 & $0.98-1.01$ & 0.951 & & & 0.139 \\
\hline Period of surgery & 1.062 & $0.70-1.60$ & 0.776 & & & 0.781 \\
\hline
\end{tabular}

OR: Odds ratio; CI: confidence interval. Bold values indicate statistical significance.

During the lockdown, we observed a reduction in incidence of well differentiated tumors. Apparently, tumors with higher grading are lesions with rapidly changing clinical features that may reveal themselves earlier and alert patients and physicians $(29,30)$. Conversely, lesions with stable clinical features associated with COVID-19 anxiety may have led to the reduction of well differentiated breast cancer incidence during the outbreak (24-31). In the next months, we may observe low grading lesions but probably in an advanced local stage.

Malignant lymph nodes involvement seems to be more frequent among the Lockdown group. We observed a significantly greater number of sentinel lymph nodes positive for cancer during the COVID-19 outbreak. In concordance with this result, incidence of ALND was significantly higher in the lockdown group. $\mathrm{N}$ staging distribution seems to be more advanced in the lockdown group with incidence of N2 being significantly higher $(32,33)$. Involvement and number of positive lymph nodes are prognostic factors of breast cancer (34-38). The higher incidence of nodes involvement and local advanced stage could be partially related to the screening suspension and delayed diagnosis (6). Additionally, we observed a different distribution of cancer grades, which could also be partially correlated with lymph nodes advanced stages (26-39). Nonetheless, at multivariate analysis, waiting time on list, significantly longer during the Lockdown, seems to be the only predictive factor of lymph nodes involvement progression. According to our results, the oncological slowdown caused by the Covid-19 lockdown, patients' anxiety and breast cancer screening suspension lead to an increase in lymph nodes advanced stages.

\section{Conclusion}

The results of breast cancer screening suspension and oncological surgical treatment delay during these months are not yet clinically evident. We reported an increase in pathological nodes involvement. Furthermore, in the comings months we might also observe an increase in tumor dimensions and incidence of clinically evident lesions with a consequent increase of post-surgery treatments and worse quality of life.
The benefit of screening is largely attributed to the ability to diagnose breast cancer in earlier stages and improve prognosis. Breast cancer screening suspension and surgical treatments delay, due to Covid-19 lockdown, could impact breast cancer presentation and staging. We did not observe a clinically evident difference in breast cancer presentation due to screening suspension and oncological treatments delay. We report an increase in lymph nodes involvement. The most significant factor predictive of major advanced $\mathrm{N}$ stage was the waiting time on list. In the coming months, we might also observe an increase in tumor dimensions and incidence and clinically evident lesions with a consequent worsening of quality of life. This study highlighted the importance of maintaining breast cancer screening programs and avoiding oncological treatment delays. This could impact clinical staging of breast cancer presentation, treatments, prognosis and quality of life of women. Resource reallocation should also take these aspects into consideration in the event of new lockdown due to second COVID-19 wave spread.

\section{Conflicts of Interest}

The Authors declare no conflicts of interest regarding this study.

\section{Authors' Contributions}

Gianluca Vanni, Leonardo Palombi, and Marco Pellicciaro: conceptualization, methodology, formal, analysis, review. Marco Pellicciaro: Writing original draft. Gianluca Vanni, Marco Pellicciaro and Jonathan Caspi: review and editing. Marco Materazzo, Orsaria Paolo, Francesca Cattadori, Francesca Combi, Simona Papi, Maria Cotesta, Chiara Adriana Pistolese, Francesca Santori, Jonathan Caspi, Antonella Grasso, Lorenza Caggiati, Roberta Raselli: data curation. Oreste Claudio Buonomo, Vittorio Altomare, Giovanni Tazzioli and Dante Palli: Supervision. All the Authors reviewed and approved the final manuscript.

\section{Acknowledgements}

This research did not receive any specific grant from funding agencies in the public, commercial, or not-for-profit sectors. 


\section{References}

$1 \mathrm{Wu} \mathrm{Z}$ and McGoogan JM: Characteristics of and Important lessons from the coronavirus disease 2019 (COVID-19) Outbreak in China: Summary of a report of 72314 cases from the Chinese Center for disease control and prevention. JAMA 323(13): 12391242, 2020. PMID: 32091533. DOI: 10.1001/jama.2020.2648

2 Ministry of Health: Covid-19 - Situazione in Italia. Available at: http://www.salute.gov.it/portale/nuovocoronavirus/dettaglioConte nutiNuovoCoronavirus.jpp?lingua $=$ italiano $\& i d=5351 \&$ area $=$ nuov oCoronavirus\&menu=vuoto [Last accessed on October 25, 2020]

3 Buonomo OC, Materazzo M, Pellicciaro M, Caspi J, Piccione E and Vanni G: Tor Vergata University-Hospital in the beginning of COVID-19-Era: experience and recommendation for breast cancer patients. In Vivo 34(3 Suppl): 1661-1665, 2020. PMID: 32503826. DOI: 10.21873 /invivo. 11958

4 Lambertini M, Toss A, Passaro A, Criscitiello C, Cremolini C, Cardone C, Loupakis F, Viscardi G, Meattini I, Dieci MV, Ferrara R, Giusti R and Maio MD: Cancer care during the spread of coronavirus disease 2019 (COVID-19) in Italy: young oncologists' perspective. ESMO Open 5(2): e000759, 2020. PMID: 32229501. DOI: 10.1136/esmoopen-2020-000759

5 Cammalleri V, Muscoli S, Benedetto D, Stifano G, Macrini M, Di Landro A, Di Luozzo M, Marchei M, Mariano EG, Cota L, Sergi D, Bezzeccheri A, Bonanni M, Baluci M, De Vico P and Romeo F: Who has seen patients with ST-segment-elevation myocardial infarction? First results from Italian Real-World Coronavirus Disease 2019. J Am Heart Assoc 9(19): e017126, 2020. PMID: 32901560. DOI: 10.1161/JAHA.120.017126

6 Curigliano G, Cardoso MJ, Poortmans P, Gentilini O, Pravettoni G, Mazzocco K,Houssami N, Pagani O, Senkus E, Cardoso F and editorial board of The Breast: Recommendations for triage, prioritization and treatment of breast cancer patients during the COVID-19 pandemic. Breast 52: 8-16, 2020. PMID: 32334323. DOI: $10.1016 /$ j.breast.2020.04.006

7 Vanni G, Pellicciaro M, Materazzo M, Palombi L and Buonomo OC: Breast cancer diagnosis in Coronavirus-Era: Alert from Italy. Front Oncol 10: 938, 2020. PMID: 32574281. DOI: 10.3389 /fonc .2020 .00938

8 Ferlay J, Colombet M, Soerjomataram I, Mathers C, Parkin D M, Pineros M, Znaor A and Bray F: Estimating the global cancer incidence and mortality in 2018: GLOBOCAN sources and methods. Int J Cancer 144(8): 1941-1953, 2019. PMID: 30350310. DOI: 10.1002/ijc.31937

9 Berry DA, Cronin KA, Plevritis SK, Fryback DG, Clarke L, Zelen M, Mandelblatt JS, Yakovlev AY, Habbema JD and Feur EJ: Cancer Intervention and Surveillance Modelling Network (CISNET) Collaboratirs. Effect of screening and adjuvant therapy on mortality from breast cancer. N Engl J Med 353(17): 17841792, 2005. PMID: 16251534. DOI: 10.1056/NEJMoa050518

10 Puliti D, Bucchi L, Mancini S, Paci E, Barraco S, Campari C, Canuti D, Cirilli C, Collina N, Conti GM, Di Felice E, Falcini F, Michiara M, Negri R, Ravaioli A, Sassoli De' Bianchi P, Serafini M, Zorzi M, Caldarella A, Cataliotti L, Zappa M and IMPACT COHORT Working Group: Corrigendum to "Advanced breast cancer rates in the epoch of service screening: The 400,000 women cohort study from Italy". Eur J Cancer 75: 109116, 2017. PMID: 28222306. DOI: 10.1016/j.ejca.2016.12.030

11 Vanni G, Pellicciaro M, Materazzo M, Bruno V, Oldani C, Pistolese CA, Buonomo C, Caspi J, Gualtieri P, Chiaravalloti A,
Palombi 1, Piccione E and Buonomo OC: Lockdown of breast cancer screening for COVID-19: Possible scenario. In Vivo 34(5): 3047-3053, 2020. PMID: 32871851. DOI: 10.21873/invivo.12139

12 Vanni G, Pellicciaro M, Materazzo M, Dauri M, D’angelillo RM, Buonomo OC, De Majo A, Pistolese C, Portarena I, Mauriello A, Servadei F, Giacobbi E, Chiaravolloti A and Buonomo OC: Awake breast cancer surgery: strategy in the beginning of COVID-19 emergency. Breast Cancer 30: 1-8, 2020. PMID: 32734327. DOI: 10.1007/s12282-020-01137-5

13 World Health Organization - Coronavirus disease 2019 (COVID19) Situation Report - 84. Available at: https://www.who.int/ docs/default-source/coronaviruse/situation-reports/20200413sitrep-84-covid-19.pdf?sfvrsn=44f511ab_2 [Last accessed on October 25, 2020]

14 Bray F, Ferlay J, Soerjomataram I, Siegel RL, Torre LA and Jemal A: Global cancer statistics 2018: GLOBOCAN estimates of incidence and mortality worldwide for 36 cancers in 185 countries [published correction appears in CA Cancer J Clin 70(4): 313, 2018]. CA Cancer J Clin 68(6): 394-424, 2020. PMID: 30207593. DOI: 10.3322/caac.21492

15 Cedolini C, Bertozzi S, Londero AP, Bernardi S, Seriau L, Concina S, Cattin F and Risaliti A: Type of breast cancer diagnosis, screening, and survival. Clin Breast Cancer 14(4): 235240, 2014. PMID: 24703317. DOI: 10.1016/j.clbc.2014.02.004

16 Buonomo O, Granai AV, Felici A, Piccirillo R, De Liguori Carino N, Guadagni F, Polzoni M, Cipriani C, Simonetti G, Cossu E, Schiaroli S, Altomare V, Cabassi A, Pernazza E, Casciani UC and Roselli M: Day-surgical management of ductal carcinoma in situ (DCIS) of the breast using wide local excision with sentinel node biopsy. Tumori 88(3): S48-9, 2020. PMID: 12365390 .

17 Senie RT, Lesser M, Kinne DW and Rosen PP: Method of tumor detection influences disease-free survival of women with breast carcinoma. Cancer 73(6): 1666-1672, 1994. PMID: 8156494. DOI: 10.1002/1097-0142(19940315)73:6<1666::aid-cncr28207306 $19>3.0 . c 0 ; 2-\mathrm{e}$

18 Burrell HC, Pinder SE, Wilson AR, Evans AJ, Yeoman LJ, Elston CW and Ellis IO: The positive predictive value of mammographic signs: a review of 425 non-palpable breast lesions. Clin Radiol 51(4): 277-281, 1996. PMID: 8617041. DOI: $10.1016 / \mathrm{s} 0009-9260(96) 80346-1$

19 Pediconi F, Galati F, Bernardi D, Belli P, Brancato B, Calabrese M Camera L, Carbonaro LA, Caumo F, Clauser P, Girardi V, Iacconi C, Martincich L, Panizza P, Petrillo A, Schiaffino S, Tagliafico A, Trimboli RM, Zuiani C, Sardanelli F and Montemezzi S: Breast imaging and cancer diagnosis during the COVID-19 pandemic: recommendations from the Italian College of Breast Radiologists by SIRM. Radiol Med 125: 926-930, 2020. PMID: 32661780. DOI: 10.1007/s11547-020-01254-3

20 Bielli A, Bernardini R, Varvaras D, Rossi P, Di Blasi G, Petrella G, Buonomo OC, Mattei M and Orlandi A: Characterization of a new decellularized bovine pericardial biological mesh: Structural and mechanical properties. J Mech Behav Biomed Mater 78: 420426, 2018. PMID: 29223730. DOI: 10.1016/j.jmbbm.2017.12.003

21 Ielpo B, Venditti D, Balassone V, Favetta U, Buonomo O and Petrella G: Proctalgia as a late complication of stapled hemorrhoidectomy. Report of our case series. Int J Surg 8(8): 648652, 2010. PMID: 20797456. DOI: 10.1016/j.ijsu.2010.07.303

22 Vidya R, Rubio IT, Paulinelli RR, Rancati A, KolacinskaVoytkuv A, Salgarello and M Becker H: Should breast 
reconstruction and breast oncoplastic procedures be performed during the coronavirus pandemic? Ecancermedicalscience 14: 1041, 2020. PMID: 32565894. DOI:10.3332/ecancer.2020.1041

23 Van de Grift TC, Mureau MAM, Negenborn VN, Dikmans REG, Bouman MB and Mullender MG: Predictors of women's sexual outcomes after implant-based breast reconstruction. Psychooncology 29(8): 1272-1279, 2020. PMID: 32419285. DOI: $10.1002 /$ pon.5415

24 Vanni G, Materazzo M, Santori F, Pellicciaro M, Cotesta M, Orsaria P, Cattadori F, Pistolese CA, Perretta T, Chiocchi M, Meucci R, Lamacchia F, Assogna M, Caspi J, Granai AV, De Majo A, Chiaravalloti A, D'Angelillo RM, Barbarino R, Ingallinella S, Morando L, Dalli S, Portarena I, Altomare V, Tazzioli $G$ and Buonomo OC: The effect of coronavirus (COVID-19) on breast cancer teamwork: A multicentric survey. In Vivo 34(3 Suppl): 1685-1694, 2020. PMID: 32503830. DOI: 10.21873/invivo.11962

25 Ielpo B, Podda M, Pellino G, Pata F, Caruso R, Gravante G, Di Saverio $S$ and ACIE Appy Study Collaborative: Global attitudes in the management of acute appendicitis during COVID-19 pandemic: ACIE Appy Study. Br J Surg, 2020. PMID: 33030744. DOI: 10.1002/bjs.11999

26 Vanni G, Materazzo M, Pellicciaro M, Ingallinella S, Rho M, Santori F, Cotesta M, Caspi J, Makarova A, Pistolese CA and Buonomo OC: Breast cancer and COVID-19: The effect of fear on patients' decision-making process. In Vivo 34(3 Suppl): 16511659, 2020. PMID: 32503825. DOI: 10.21873/invivo.11957

27 Giudici F, Bortul M, Clagnan E, Del Zotto S, Franzo A, Giordano L, Gobbato M, Puliti D, Serraino D, Zucchetto A, Zainer L, Zanconati $\mathrm{F}$ and Bucchi L: Effetti precoci dell'adesione al programma di screening mammografico della Regione Friuli Venezia Giulia sull'incidenza del cancro della mammella in stadio avanzato: uno studio di coorte [Early effects of attendance to the Friuli Venezia Giulia (Northern Italy) mammography screening programme on the incidence of advanced-stage breast cancer: a cohort study]. Epidemiol Prev 44(2-3): 145-153, 2020. PMID: 32631014. DOI: 10.19191/EP20.2-3.P145.037

28 Chiricozzi A, Faleri S, Saraceno R, Bianchi L, Buonomo O, Chimenti S and Chimenti MS: Tofacitinib for the treatment of moderate-to-severe psoriasis. Expert Rev Clin Immunol 11(4): 443455, 2015. PMID: 25666451. DOI: 10.1586/1744666X.2015. 1013534.

29 Warren SL, Bhutiani N, Agle SC, Martin RCG 2nd, McMasters $\mathrm{KM}$ and Ajkay $\mathrm{N}$ : Differences between palpable and nonpalpable tumors in early-stage, hormone receptor-positive breast cancer. Am J Surg 216(2): 326-330, 2018. PMID: 29502856. DOI: $10.1016 /$ j.amjsurg.2018.02.020

$30 \mathrm{Li}$ J, Chen Z, Su K and Zeng J: Clinicopathological classification and traditional prognostic indicators of breast cancer. Int $\mathrm{J}$ Clin Exp Pathol 8(7): 8500-8505, 2015. PMID: 26339424.

31 Chu J, Yang D, Wang L and Xia J: Nomograms predicting survival for all four subtypes of breast cancer: a SEER-based population study. Ann Transl Med 8(8): 544, 2020. PMID: 32411767. DOI: $10.21037 / \mathrm{atm}-20-2808$
32 Pellicciaro M, Granai AV, Marchese G, Materazzo M, Cotesta M, Santori F,Giacobbi E, Servadei F, Gelli S, Perretta T, Meucci R, Pistolese CA and Vanni G: Breast cancer patients with hormone neoadjuvant bridging therapy due to asymptomatic Corona virus infection. Case report, clinical and histopathologic findings. Int J Surg Case Rep 76: 377-380, 2020. PMID: 33052300. DOI: 10.1016/j.ijscr.2020.10.020

33 Orsaria P, Varvaras D, Vanni G, Pagnani G, Scaggiante J, Frusone F, Granai AV, Petrella G and Buonomo OC: Nodal status assessment in breast cancer: strategies of clinical grounds and quality of life implications. Int J Breast Cancer 2014: 469803, 2014. PMID: 24672730. DOI: $10.1155 / 2014 / 469803$

34 Piazza A, Adorno D, Poggi E, Borrelli L, Buonomo O, Pisani F, Valeri M, Torlone N, Camplone C, Monaco PI, Fraboni D and Casciani CU: Flow cytometry crossmatch: a sensitive technique for assessment of acute rejection in renal transplantation. Transplant Proc 30(5): 1769-1771, 1998. PMID: 9723274. DOI: 10.1016/s0041-1345(98)00423-0

35 Ferroni P, Roselli M, Spila A, D'Alessandro R, Portarena I, Mariotti S, Palmirotta R, Buonomo O, Petrella G and Guadagni F: Serum sE-selectin levels and carcinoembryonic antigen mRNA-expressing cells in peripheral blood as prognostic factors in colorectal cancer patients. Cancer 116(12): 2913-2921, 2010. PMID: 20336782. DOI: 10.1002/cncr.25094

36 Largillier R, Ferrero JM, Doyen J, Barriere J, Namer M, Mari V, Courdi A, Hannounlevi JM, Ettore F, Birtwisle-Peyrottes I, Balu-Maestro C, Marcy PY, Raoust I, Lallement M and Chamorey E: Prognostic factors in 1,038 women with metastatic breast cancer. Ann Oncol 19: 2012-2019, 2008. PMID: 18641006. DOI: $10.1093 /$ annonc/mdn424

37 Hortobagyi GN, Edge SB and Giuliano A: New and important changes in the TNM staging system for breast cancer. Am Soc Clin Oncol Educ Book 38: 457-467, 2018. PMID: 30231399. DOI: 10.1200/EDBK_201313

38 Vanni G, Materazzo M, Pellicciaro M, Morando L, Portarena I, Anemona L, D'angelillo RM, Barbarino R, Chiaravalloti A, Meucci R, Perretta T, Deiana C, Orsaria P, Caspi J, Pistolese CA and Buonomo OC: Does age matter? Estimating risks of locoregional recurrence after breast-conservative surgery. In Vivo 34(3): 11251132, 2020. PMID: 32354901. DOI: 10.21873/invivo.11884

39 Kolarova I, Vanasek J, Dolezel M, Stuk J, Hlavka A, Dusek L, Melichar B, Buchler T, Ryska A, Prausova J, Petrakova K, Tesarova P, Petera J, Vosmik M, Horackova K and Jarkovsky J: Association of triple positivity with prognostic parameters and overall survival in a population-based study of 6,122 HER2positive breast cancer patients: analysis of real-world clinical practice based on a research database. Neoplasma, 2020. PMID: 32614235. DOI: 10.4149/neo_2020_191023N1080

Received November 10, 2020

Revised November 17, 2020

Accepted November 18, 2020 